\title{
A PLURALIST INTERPRETATION OF THOMAS KUHN'S PHILOSOPHICAL POSITION
}

\author{
UNA INTERPRETACIÓN PLURALISTA DE LA POSICIÓN \\ FILOSÓFICA DE THOMAS KUHN
}

\section{Paula Luz Atencia Conde-Pumpido*}

\begin{abstract}
It is commonplace in philosophical literature to attribute to Thomas Kuhn a philosophical view at odds with (scientific) realism, especially an idealist position rooted in the Kantian distinction between "world-in-itself" and "world of appearances". In this paper I will argue that Kuhn's philosophical view is amenable to a pluralist interpretation that fits better into his general philosophy of science. In addition, this pluralist approach to Kuhn's philosophical position also provides an alternative view on incommensurability, whose central feature is represented by the taxonomical and ontological disparity that exists between rival or successive scientific specialties.
\end{abstract}

Keywords: pluralism, incommensurability, natural kinds, taxonomy, ontological disparity.

\section{Resumen}

Es habitual encontrar en la bibliografía filosófica en torno a la figura de Thomas Kuhn la atribución a este autor de una concepción filosófica reñida con el realismo (científico), y en especial una posición de tipo idealista que hunde sus raíces en la distinción kantiana entre "mundo-en-sí mismo" y "mundo de las apariencias". En este artículo defiendo que la concepción filosófica de Kuhn admite una interpretación pluralista que encaja mejor con su filosofía de la ciencia general. Además, esta interpretación pluralista de la posición filosófica de Kuhn también permite ofrecer una explicación alternativa del fenómeno de 
la inconmensurabilidad, cuya característica central estaría representada por la disparidad taxonómica y ontológica que existe entre especialidades científicas rivales o sucesivas.

Palabras clave: pluralismo, inconmensurabilidad, géneros naturales, taxonomía, disparidad ontológica.

Recibido: 2019-05-3I

Aceptado: 2020-03-05

\section{Introduction}

Since the publication of The Structure of Scientific Revolutions (Kuhn I962; $2^{\text {nd }}$ edition, 1970) Thomas Kuhn's views have been widely discussed in philosophical literature, especially those concerning scientific change and incommensurability, which are usually presented as a threat to scientific realism. Accordingly, it has generally been assumed that $\mathrm{Ku}-$ hn's philosophy is at odds with this position, and that its central theses entail either a relativist or an antirealist view. In this vein it has also been commonplace to attribute to him an idealist position rooted in the Kantian distinction between "world-in-itself" and "world of appearances". Such an idealist interpretation seems to be supported by Kuhn's writings, in which he sometimes establishes similarities between Kant's philosophy and his own (see, e.g., Kuhn I99I and 200ob).

In this paper I argue that Kuhn's philosophical view is amenable to a pluralist reading that fits better into his general philosophy of science. Additionally I will show that this pluralist approach also provides a framework for developing an alternative view on incommensurability according to which the central feature of this phenomenon is represented by the taxonomical and ontological disparity that exists between rival or successive scientific specialties. Section 2 presents a comprehensive outlook of Kuhn's general philosophical view by delineating its central arguments. In section 3 I will show that, contrary to what some of Kuhn's own claims may suggest, there are reasons to avoid attributing to him an idealist position. In section 4 I offer a pluralist interpretation of Kuhn's main philosophical arguments and introduce further important elements in his philosophy that can also be connected to pluralist approaches to science. Finally, section 5 provides an account on incommensurability in accordance with the pluralist reading of Kuhn's philosophy portrayed in the previous section. 


\section{A comprehensive overview of Kuhn's main philosophical arguments}

The incommensurability thesis is without question one of the central elements of Kuhn's work. However, the references to incommensurability in The Structure of Scientific Revolutions are scarce. In fact, his work of 1962 does not address this topic directly. Instead it deals mainly with two themes, namely the concept of paradigm and scientific change, and incommensurability is presented as a consequence of a series of theses concerning those issues.

As Kuhn becomes gradually more concerned with clarifying his incommensurability thesis, he also gets involved in debates related to the philosophy of language. This is so because the phenomenon of incommensurability includes a linguistic element, which manifests itself in communication problems experienced by advocates of successive or rival paradigms ${ }^{1}$. For this reason Kuhn surely thought that the phenomenon of incommensurability could be further elucidated by examining the nature of these communication problems. In any case, this shift in his intellectual career has led some of Kuhn's commentators to claim that after the publication of The Structure of Scientific Revolutions his work shows an important change in its subject matter - and also in its methodology (see especially Bird 2004a).

While it is undeniable that there are significant shifts in Kuhn's viewpoints as well as a considerable narrowing of focus throughout his career, it is also possible to find a common thread throughout his early and later writings that may serve as the basis to provide a comprehensive overview of his philosophy.

As mentioned above, the main themes in Kuhn's work of 1962 are the notion of paradigm and scientific change. In the Postscript to The Structure of Scientific Revolutions Kuhn remarks that his use of the notion of paradigm in this work included two different senses, which he further clarifies. Each of these senses of the concept of paradigm proves to be a key element of his philosophical thought.

I Hereafter I will use the terms "rival", "successive", "competing" and "incommensurable" as interchangeable when referred to paradigms. Furthermore, these qualifiers can also be applied to terms such as theories, taxonomies or scientific specialties since, after the publication of The Structure of Scientific Revolutions, where Kuhn applies the term "incommensurable" mainly to paradigms, he gradually abandons this later notion in favor of those previously quoted. 
In a broad sense a paradigm refers to the set of commitments that holds a scientific community together. These commitments have a strong impact on scientific practice, for they significantly shape the activities that scientists undertake, the problems that they address, and the products that they develop -such as scientific theories. In the light of this, a dependency relation can be established between a paradigm, understood in this broad sense, and scientific practice. In other words, scientific practice is always relative to a paradigm.

In a more restricted sense the notion of paradigm is related to that of "exemplar", whose meaning is in turn closely linked to the acquisition of mental sets (Kuhn I959, p. 229) or cognitive capacities (cf. Bird 2004b and 2007) that are part of the conceptual tools employed by scientists in their professional practice.

A relevant connection may be established between the process of education in a paradigm, the notion of exemplar, and the acquisition of cognitive capacities. Exemplars are concrete problem solutions generally accepted by a scientific community, and they serve as models when solving more complex problems. When educated in a paradigm students are introduced to these exemplars, and they are asked to solve problems that are very similar to them. Such problems normally make use of concepts that are central to the scientific practice conducted within the paradigm, so during their training process students get acquainted with notions that will become essential to their professional career.

Repeated exposure and practice will give the students the ability to tackle harder problems, an ability that is not merely a matter of applying or following rules. In order for the students to solve more difficult problems they should be able to establish similarities between them and those they have already solved. Thus, during the process of paradigm-education students acquire mental sets that allow them to recognize similarities between certain problems and the concepts involved in them. More specifically, these mental sets supply the capacity to identify a network of similarity relations ${ }^{2}$ between concepts, and consequently

2 In some of his writings Kuhn claims that the similarity relations between the instances of a concept do not depend only on their likeness but also on their differences from instances of other concepts. Hence, the mere exposition to resemblances between the instances of a concept may not suffice to apprehend the similarity relations central to a paradigm, and the presentation of dissimilarities from other instances plays an essential role in acquiring them (see, e.g., 1974, p. 307, 1976, p. 194, n. 27, 1983, p. 5I). In this respect, the expositions to instances of concepts that constitute contrast sets enable the learner to acquire those dissimilarity relations. For example, when a child is learning the concept waterfowl, the exposition to ducks, geese, and swans -which form a contrast 
between the individuals comprised in such concepts.

One last fundamental thesis included in The Structure of Scientific Revolutions is the so-called "world-change thesis", which states that "when paradigms change, the world itself changes with them" (Kuhn I970, p. III). This thesis is directly related to the most radical aspect of scientific change, and I believe that it can be considered representative of Kuhn's philosophy. Its specific meaning and scope will be elucidated later on (see section 4).

As already noted, after the publication of The Structure of Scientific Revolutions Kuhn became more and more interested in the linguistic elements involved in the incommensurability thesis. His writings in the I980s and the I990s are largely inspired by his insight that the processes of learning the language of a theory and of learning something about nature are two faces of the same coin. On this matter, he claims that "in much of language learning these two sorts of knowledge -knowledge of worlds and knowledge of nature- are acquired together" (Kuhn 1987, p. 3I), or in more controversial terms "different languages impose different structures on the world" (Kuhn I983, p. 52). These ideas constitute the core of his taxonomic version of incommensurability, according to which two theories are incommensurable if they employ non-homologous lexical taxonomies, that is, lexicons or taxonomies with different structures.

In this regard a terminological clarification is appropriate. Kuhn usually employs the terms "taxonomy", "lexical taxonomy" or "lexicon" as interchangeable, for example when he asserts that a lexicon is "the shared taxonomy of a speech community" (Kuhn I99I, p. IOI), and I will focus on this use. He also characterizes a lexicon in a partially different way, i.e., as a "structured vocabulary" (Kuhn I989, p. II and I990, p. 300) of kind terms that "embodies the shared conceptual or taxonomic structure that holds [a speech] community together" (Kuhn I99I, p. I04), where that conceptual or taxonomic structure is formed by a set of taxonomic categories arrayed in a particular way on the basis of some similarity and dissimilarity relations among the members of natural kinds. On the other hand, it is important to emphasize that a lexicon "contains both kind concepts and their names" (Kuhn 1993, p. 229); thus when speaking

set- will play an important role in his acquisition of the concept (see Kuhn 1974). For this reason, hereafter I will include these dissimilarity relations as part of the network of relations that students learn during their educational process -and later on also as part of the network of relations that make up a taxonomy. 
about a lexicon, taxonomy, etc. we could speak indistinctly of taxonomic categories, kind concepts and kind terms.

The process of language learning brings with it the acquisition of a particular taxonomy, which is employed in describing the world (or a part of it). A taxonomy can be conceived as a set of kind terms hierarchically structured in accordance to some similarity and dissimilarity relations among the members of their extensions. Competing or successive theories are incommensurable because they contain non-homologous lexical taxonomies, and thus taxonomies that make use of incompatible or discrepant similarity and dissimilarity relations, as a result of which they contain natural kind terms whose referents overlap3. This explains why incommensurable theories are not fully translatable, namely because non-homologous taxonomies cannot be fused or combined "without residue or loss" (Kuhn I983, p. 36) as they contain kind terms whose corresponding kinds overlap in membership.

Before addressing the particular consequences that can be derived from the taxonomic formulation of incommensurability with regard to Kuhn's philosophical position -a task that will be addressed in section $4^{-}$it is important to note that it is possible to establish a common thread in his work between the taxonomic structures that are the key to this later formulation of incommensurability and the mental sets or cognitive capacities that appear in his early writings. For both cognitive capacities and taxonomical structures come with an associated way of organizing a given collection of individuals, which represents a fundamental aspect of scientific specialties (see footnote I), in particular the way science is conducted within them.

Given this parallelism, on the one hand, and the important role cognitive capacities and/or taxonomic structures play in Kuhn's work, on the other, it is reasonable to claim that they can be taken as paramount to the specification of his philosophical view, which could be stated as follows. During their training period in a scientific discipline, scientists acquire some conceptual tools that allow them to recognize networks of relations among individuals that, taken together, constitute a taxonom-

3 As Kuhn develops his taxonomic version of incommensurability he introduces the no-overlap principle as an important feature of such phenomenon. According to this principle "no two kind terms, no two terms with the kind label, may overlap in their referents unless they are related as species to genus" (Kuhn I99I, p. 92). However, this is exactly what happens in the case of incommensurable taxonomies, namely, the same kind term appears in those taxonomies, and the corresponding kinds overlap in membership. 
ical structure -or just a taxonomy-, that is, a hierarchical form of organization of a collection of individuals which is always relative to a scientific discipline and is essential to understand how science is conducted within that discipline.

Scientists who carry out their professional practice under the guidance or incommensurable scientific specialties will rely on theories that presuppose non-homologous taxonomies, and hence incompatible organizations of the same collection of individuals. In other words, scientists, in their daily work and research, make implicit or explicit use of taxonomies that, in the case of incommensurable disciplines, classify the same individuals in ways that are not mutually consistent.

\section{Why Kuhn's philosophy is not idealist}

It has been widely assumed that Kuhn maintains a philosophical position akin to idealism in which the Kantian distinction between "worldin-itself" and "world of appearances" plays a central role. This approach to Kuhn's philosophy has been suggested and further developed especially by Paul Hoyningen-Huene (1993), who offers a reconstruction of Kuhn's philosophical position that is based on the assumption that $\mathrm{Ku}-$ hn's use of the term "world" in The Structure of Scientific Revolutions includes two different senses.

On the one hand, "world" would refer to a world (or a part of it) that is completely independent of any conceptual contribution coming from an epistemic subject or, more generally, a paradigm. On the other hand, "world" would also refer to a world which is already conceptually subdivided in accordance with a paradigm. Taken together, both senses of the term world compose a "phenomenal world". Thus a phenomenal world is constituted by an "objective-sided-world", which can be identified to Kant's world-in-itself, and a "subjective-sided-world", which resembles the world of appearances in Kant's philosophy.

There is certainly no doubt that there are important parallelisms between Kant and Kuhn. As explained in the previous section, Kuhn claims that scientific practice is always relative to a paradigm or scientific specialty, which provides its members with a set of conceptual tools that are crucial to successfully conducting their research. In this sense, the knowledge contained in scientific theories accepted or developed in a scientific specialty is importantly shaped by the conceptual framework ${ }^{4}$

4 In writings that deal with the taxonomic formulation of incommensurability 
(i.e., taxonomy or taxonomical structure) assumed by that specialty. Furthermore, insofar as a conceptual framework amounts to a particular classification of the world, incommensurable scientific specialties, which employ non-homologous conceptual frameworks, will conceptualize the world in dissenting ways.

As a consequence of the above it can be claimed that the world depicted by scientific theories is always conceptually organized in accordance with a paradigm, which certainly seems to support idealist interpretations of Kuhn's philosophy that appeal to the Kantian distinction between a world-in-itself, independent of any conceptualization originated in an epistemic subject, and a world of appearances, a world already conceptually organized. Hence, both philosophers recognize the important part played by a set of cognitive elements in the production of knowledge. However, there is a significant difference between their views. While Kant grants such cognitive elements a universal character so that they represent a fixed part of our way to configure experience as human beings, Kuhn conceives them as dynamic, which entails adding a further addendum to this idealist interpretation of his philosophical position.

For Kuhn, the subject-sided-world is always relative to a paradigm, and as such it changes when a paradigm does. When the subject-sided-world is altered after a revolutionary period as a consequence of a change of paradigm, the phenomenal world is also transformed. But such change does not affect the object-sided-world, which remains stable through revolutionary changes.

If we take into consideration the Kuhnian model of scientific development in which periods of normal science -periods in which scientific activity is always carried out under the guidance of a paradigm- are always followed by revolutionary periods that lead to the abandonment of the paradigm accepted until then and its subsequent replacement by a different, incommensurable paradigm ${ }^{5}$, we might expect that the phenomenal world be constantly changing. Thus a fundamental assump-

Kuhn sometimes employs the terms "conceptual scheme" and "lexical taxonomy" as analogous (see, e.g., Kuhn I99I, p. 94). In view of the terminological clarification presented in section 2 concerning taxonomic incommensurability, I will employ the terms conceptual scheme and taxonomic structures interchangeably, as well as taxonomy and conceptual framework.

5 Revolutionary periods do not necessarily lead to the abandonment of the paradigm accepted at the time. Sometimes crises can be resolved employing the means provided by that paradigm. 
tion in Kuhn's philosophy is that there is a "plurality of worlds", and such worlds include an objective-sided element that is forever fixed, but also unattainable and unknowable, very much like the Kantian worldin-itself.

As if the similarities between Kant's and Kuhn's philosophical views specified above were not enough, Kuhn comes to recognize himself as a "Kantian with movable categories" (Kuhn 200ob, p. 264), and that the position he aims to develop is a sort of "post-Darwinian Kantianism" (Kuhn 1991, p. I04), which has been taken by many of his commentators as uncontroversial evidence that his philosophy includes an idealist slant rooted in the Kantian distinction between two worlds or realms. This distinction would also lead to the specification of two different epistemological and ontological levels, one objective and independent of any cognitive activity originated in the epistemic subject, and another subjective and dependent on it. Faced with this differentiation one seems almost forced to ask whether it is possible to have access to the objective, independent world or rather our knowledge is always mediated by cognitive elements that preclude any direct access to it. For Kuhn, the world-in-itself is mostly unknowable, since in his view it is possible to say some things about it, for example that it exists outside space and time (cf. Kuhn I99I, p. I04).

In any case, this interpretation of Kuhn's philosophy may be adequate to explain his view in The Structure of Scientific Revolutions, but it cannot be taken as a general account of his philosophical position mainly because he rejects the Kantian notion of world-in-itself in later writings:

The view toward which I grope would [...] be Kantian, but without "things in themselves" and with categories of the mind which could change with time as the accommodation of language and experience proceeded (Kuhn 1979, p. 207).

6 In some of his personal notes Kuhn explains that years before the publication of The Structure of Scientific Revolutions he was inspired by the work of Jean Piaget, especially because he differentiated between two worlds -the psychological world and the real world- that he had already considered as independent of each other (cf. Mayoral 2017). Accordingly, it is reasonable to claim that Kuhn's philosophical position in The Structure of Scientific Revolutions can be explained by taking into account the aforementioned distinction between two different worlds. 
Kuhn's denial of the concept of things-in-themselves ${ }^{7}$ alters his position in an important sense, for it can no longer be explained by resorting to the differentiation between two distinct worlds. However, the thesis of the plurality-of-worlds attributed to him by Hoyningen-Huene captures something substantial of his philosophical stance. The combination of these two elements (namely the plurality of worlds thesis and the denial of the concept of things in themselves) can be taken as central to Kuhn's philosophical view.

\section{A pluralist interpretation of Kuhn's philosophy}

As explained in section 2 Kuhn's early writings largely deal with the idea that the period of education in a paradigm aims at transmitting a series of cognitive tools that are essential to conducting future professional practice in a scientific specialty. During their training period students learn to recognize similarity and dissimilarity relations among a given collection of individuals, and these relations make up a particular form of classification of such individuals. Therefore, students learn how to organize a part of the world in accordance with a network of relations.

Similarly, in Kuhn's later writings learning the language of a scientific community involves learning the taxonomical structure embedded in that language, where a taxonomical structure is just a taxonomy -namely a hierarchical form of organization of a number of objects. Therefore, Kuhn's central argument is that practice within a scientific specialty is always conducted according to a series of commitments, among which there is the assumption of a particular taxonomy. Competing or successive scientific specialties are incommensurable precisely when they entail disparate taxonomies, that is, when they organize the world in non-homologous ways. This key feature of incommensurability gives rise to an important question: if incommensurable scientific specialties assume incompatible taxonomies, which taxonomy matches the world's real joints?

At some point in his writings, Kuhn identifies the Kantian worldin-itself, which he rejects, with a world with joints (cf. Kuhn 1979). Thus it can be argued that Kuhn does not commit himself to either of these

7 Here it should be noted that Kuhn wasn't totally sure about this point, that is, whether his philosophical position could do without the world in itself (in conversation with Paul Hoyningen-Huene). In any case, it can be argued that his general philosophy makes greater sense along such lines, as I hope it will become more evident henceforth. 
notions, or to the claim that there is a fundamental taxonomy that reveals the objective, independent structure of the world, hence carving nature at its joints. The thesis that there is no world with joints, which represents a central element in Kuhn's philosophy, can be reformulated by claiming that the world is not pre-divided into privileged objects and kinds of objects, and therefore there are many possible ways in which we can organize independent reality. Also, this thesis has a further, crucial consequence with respect to Kuhn's philosophical view. Taxonomies come with an associated ontology, since they define which individuals exist and what they are. Therefore, if there is no fundamental taxonomy, there cannot be a fundamental ontology either. In other words, as there is no uniquely correct way of organizing the (independent) world into kinds, there is no privileged ontology that could describe the world. Instead, there are multiple ontologies available, each of which is relative to a particular taxonomy. It is reasonable, then, to attribute to Kuhn a pluralist view about ontology which, in turn, results from considerations regarding scientists' classificatory practices -and hence, from his taxonomical pluralism.

Kuhn's pluralist view does not include any distinction between two epistemological or ontological realms, for he rejects the notion of a world with joints, and consequently the thesis that "a given thing or system of things can [only] be described in [...] one way, if the description is supposed to be complete and correct, and that way is supposed to fix exactly one 'ontology'" (Putnam 2015, p. 84). Thus Kuhn's philosophy is at odds with metaphysical realism. This has led many of his interpreters to claim that his philosophy is clearly antirealist. However, in recent decades several philosophers of science who maintain views akin to pluralism have defended that metaphysical realism is not indispensable to scientific realism (see, e.g., Chakravartty $201 \mathrm{I}$ and Kitcher 20I2).

Kuhn's ontological pluralism is the cornerstone of his controversial world-change thesis, according to which "after a revolution scientists are responding to a different world" (Kuhn 1970, p. III). The significance of this thesis lies in the fact that after revolutionary periods scientists describe the world using an ontology that differs from the one previously accepted. In this sense, the world-change thesis could be better dubbed the ontology-change thesis.

Having reached this point it is relevant to indicate that in his later writings Kuhn presents an account on scientific progress that focuses on specialization rather than unification (Kuhn I99I). During scientific revolutions new fields of knowledge usually emerge, and they coexist with 
each other during a given period of time. These cognitive specialties are largely incommensurable, which means that the taxonomical and ontological disparity that goes hand in hand with it -and, in turn, taxonomical and ontological pluralism-is not only a diachronic phenomenon, but a synchronic one too. Therefore, multiple alternative ontologies may coexist at a given time.

Kuhn's account on scientific progress also entails that the coexistence between incommensurable scientific specialties, and hence between the ontologies that they pose, be a key feature of science, and not a temporary state of affairs. He rejects the idea of a complete, all-encompassing account of nature -one that "fits exactly one ontology," as Putnam puts it- towards which scientific theories progressively approach. Moreover, Kuhn questions the relevance of such an account, even if it did exist:

We are all deeply accustomed to seeing science as the one enterprise that draws constantly nearer to some goal set by nature in advance. But need there be such goal? [...] Does it really help to imagine that there is some one full, objective, true account of nature and that the proper measure of scientific achievement is the extent to which it brings us closer to that ultimate goal? (Kuhn I970, p. I7I).

These considerations are motivated by his idea that scientific progress is driven by specialization rather than by unification. Revolutionary periods lead to the proliferation of new fields of knowledge which gradually become more and more specialized due to the isolation they experience from the rest of specialties. The increasing specialization experienced by these scientific specialties allow them to refine their cognitive tools, which in turn enhance their ability to solve problems, which is the ultimate goal of science understood as a global enterprise.

It is incommensurability that fosters the necessary isolation between new fields of knowledge so that they can undergo a process of specialization that will turn them into well-established scientific disciplines. Incommensurability induces these new fields to develop their own language, taxonomical practices, etc. which indeed separate them from the rest of the disciplines, but also allow them to acquire the conceptual means to solve problems efficiently. Therefore, incommensurability is an unavoidable feature of science, but a positive one after all, as it promotes scientific progress in the Kuhnian sense. Accordingly, achieving a complete account of nature is at odds with the development of science, which depends on the proliferation of new scientific specialties, not their unification. 
The thesis that there is no meaningful enterprise of finding a complete account of nature has also been defended by pluralist philosophers of science (see, e.g., Kellert et al. 2006 and Kitcher 2012), which provides further connections between Kuhn's general philosophy of science and pluralism.

\section{Incommensurability as taxonomical and ontological disparity}

In line with the arguments regarding taxonomical and ontological pluralism that have been specified in the previous section incommensurability can be described as the thesis that theories separated by a scientific revolution, or theories that are part of dissenting scientific specialties are incompatible from a taxonomical and ontological perspective. What changes during scientific revolutions is part of the taxonomy of scientific theories, and consequently also part of the ontology embedded in such taxonomies. It is reasonable to think, then, that there can be cases where incommensurability is more problematic than others as the discordances between competing theories affect a greater part of the taxonomies and ontologies assumed by such theories.

At this point a comment is advisable. Kuhn sustains a semantic local holism by virtue of which he restricts incommensurability to a set of interrelated terms that are part of the taxonomies assumed by theories. Incommensurable theories share a great part of their vocabulary and conceptual apparatus, but they also include a group of terms that interdefine each other and whose meaning and reference differ from one theory to another. Leaving aside the problems that "local incommensurability" ( $c f$. Kuhn 1983) generate ${ }^{8}$, it can be claimed that incommensurability only affects a detectable, restricted part of the taxonomical structure employed by a scientific community, and hence only a localized part of the ontology that taxonomy entails.

This approach to incommensurability, which emphasizes the taxonomical and ontological disparity that exists among competing theories, can also accommodate the linguistic element involved in this phenomenon. It should be remembered that advocates of incommensurable theories encounter some problems when they try to communicate to each

8 Kuhn himself confesses that he was not able to make full sense of his local incommensurability. It is not clear how it is possible that the set of interrelated terms that are subject to incommensurability do not infect the rest of terms in the taxonomy, and hence how incommensurability can be restricted to a local region (Kuhn 1983). 
other, especially during the processes of comparison and evaluation of their favorite theories (Kuhn 1970). As mentioned above these communication problems are restricted to a localized part of the vocabulary included in the taxonomies assumed by these individuals, particularly to a set of interrelated terms to which they attribute a different meaning and reference.

In section 2 taxonomies were defined as sets of natural kind terms structured in accordance to some similarity and dissimilarity relations among the members of their extensions. Thus similarity and dissimilarity relations organize a particular set of natural kinds, and the corresponding natural kind terms, and in so doing they affect the way in which membership into such kinds is determined. In other words, similarity and dissimilarity relations are relevant to the determination of the reference of kind terms, which means that their modification may lead to changes in the extension of such terms.

During scientific revolutions, the similarity and dissimilarity relations that make up the taxonomy embedded in the theories accepted by a scientific community experience some modifications: "One of the things (perhaps the only thing) that changes in every scientific revolution is some part of the network of similarity [and dissimilarity] relations" (Kuhn 1976: 194) employed in structuring a set of kind terms. Hence part of that taxonomy is redesigned, that is, some natural kinds included in the taxonomy are re-classified in accordance with different similarity and dissimilarity relations, which leads to changes in the meaning and reference of the corresponding natural kind terms. The resulting taxonomy will be incommensurable with the previous one as a consequence of these modifications, and it will also contain natural kind terms that overlap in their referents.

Thus, incommensurable taxonomies classify the same individuals under overlapping natural kinds -hence attributing different extensions to the corresponding natural kind terms- in virtue of their use of discrepant similarity and dissimilarity relations. An example of this is provided by the Ptolemaic and the Copernican astronomical taxonomies. According to the former, the moon and the sun are part of the extension of the term "planet", but not the earth. By contrast, the latter includes the earth into the extension of the term "planet" while the sun and the moon are no longer part of its extension -the sun is part of the extension of the term "star", while the moon is a new sort of body, a satellite (Kuhn 1987). These taxonomies employ different criteria for membership into some natural kinds, and so their corresponding terms will have different 
extensions in both taxonomies. As a consequence, supporters of incommensurable taxonomies will probably encounter communication problems when employing some terms, for in doing so they will be referring to different individuals.

The linguistic difficulties experienced by supporters of incommensurable theories include verbal issues, but not merely verbal; they are also conceptual and ontological disagreements because the individuals engaged in conversation presuppose incompatible taxonomies, and hence dissenting ontologies. As a consequence, the resolution of these disagreements cannot be achieved merely by noticing that they are using some words in a different way (i.e., they attribute some terms a different reference). In fact, such disagreements appear to be rather unresolvable. On the one hand, it is not possible to establish successful reduction relations among incommensurable theories. In this context, successful reduction relations need to be understood as reductions that retain every particular feature included in the taxonomies of incommensurable theories, including the similarity and dissimilarity relations employed in both taxonomies. In view of this, attempts to reduce one incommensurable theory to another or fuse them together into an all-encompassing, neutral framework do not proceed "without residue or loss" (Kuhn I983, p. 36). On the other hand, ontological disagreements that emerge between advocates of incommensurable theories cannot be resolved by claiming that the supporters of one of such theories are simply mistaken in their assumptions about which entities exist and how they are structured. In Kuhn's view there is neither a fundamental taxonomy nor an essential ontology that carves nature at its joints. Accordingly it is not possible to resolve ontological disagreements by clinging to a fundamentalist metaphysical view.

In sum, the communication problems experienced by advocates of incommensurable theories are a consequence of the taxonomical and ontological disparity that exists among such theories, which is the cornerstone of incommensurability. Ontological disparity is also revealed in the various metaphysical commitments held by members of successive or competing scientific specialties. After revolutionary periods some scientific specialties typically redesign their ontological landscape either by eliminating or adding entities to it - normally both. Accordingly, after scientific revolutions scientists have suspended their belief in the existence of certain individuals and committed themselves to the existence of novel entities. In addition, they may also have replaced the metaphysical characterizations they made about certain entities with 
incompatible ones. Likewise competing theories generally invoke ontologies and metaphysical commitments inconsistent with each other.

The taxonomical and ontological disparity that characterizes incommensurable theories is not resolvable, or at least not in the ways described above. Thus incommensurability appears to be an unavoidable feature of science.

\section{Conclusion}

In this paper I have argued that Kuhn's philosophical position is amenable to a pluralist interpretation which also provides a sensible explanation of the phenomenon of incommensurability. In particular, I have attributed to Kuhn a pluralist view about taxonomy and ontology according to which there are many possible ways to organize reality, each entailing a particular ontology. Accordingly, there are multiple ontological descriptions of the world, but none of them are privileged or fundamental. In addition, incommensurability can be understood as the taxonomical and ontological disparity that exists between successive or competing scientific specialties. These specialties typically develop their own conceptual tools, among which there is a particular taxonomy, namely a set of natural kinds hierarchically structured in accordance to some similarity and dissimilarity relations. Successive or competing scientific specialties are incommensurable because they assume non-homologous taxonomic structures, that is, taxonomies that make use of incompatible similarity and dissimilarity relations. As a result, incommensurable specialties also presuppose dissenting ontologies. The taxonomical and ontological disparity that typifies incommensurable specialties also explains the communication problems experienced by members of competing or successive specialties when they engage in conversation, and hence the linguistic element involved in incommensurability.

Acknowledgments: A version of this paper was presented at the Complutense-Lisbon Meeting in Analytic Philosophy held at Complutense University of Madrid in 20I9, and I would like to thank the organizers and the audience. I also benefited from discussions and feedback from various people, including Luis Fernández Moreno, Ana Rosa Pérez Ransanz, Paul Hoyningen-Huene and Juan Vicente Mayoral. 


\section{References}

Bird, A. (2004a). "Kuhn's wrong turning". Studies in History and Philosophy of Science Part A, 33 (3): 443-463.

(2004b). "Naturalizing Kuhn". Proceedings of the Aristotelian Society I05 (I): 99-II7.

(2007). "Incommensurability naturalized". In L. Soler, H. Sankey and P. Hoyningen-Huene (eds.), Rethinking Scientific Change and Theory Comparison: Stabilities, Ruptures, Incommensurabilities?, 2I-39. Boston: Springer.

Chakravartty, A. (20II). "Scientific Realism and Ontological Relativity". The Monist 94 (2): $157-80$

Hoyningen-Huene, P. (1993). Reconstructing Scientific Revolutions. Chicago: Chicago University Press.

Kellert, S. H., H. E. Longino, and C.K. Waters (eds.) (2006). Scientific Pluralism. Minnesota Studies in the Philosophy of Science XIX. Minneapolis: University of Minnesota Press.

Kitcher, P. (2012). Preludes to Pragmatism: Toward a Reconstruction of Philosophy. Oxford: Oxford University Press.

Kuhn, T.S. (1959). "The Essential Tension: Tradition and Innovation in Scientific Research". In T.S. Kuhn (1977): 225-239.

(1970). The Structure of Scientific Revolutions ( $2^{\text {nd }}$ ed.). Chicago: Chicago University Press; $\mathrm{I}^{\text {st }}$ edition, 1962.

(1974). "Second Thoughts on Paradigms". In F. Suppe (ed.), The Structure of Scientific Theories, Urbana, University of Illinois Press. Reprinted in T.S. Kuhn, The Essential Tension: Selected Studies in Scientific Tradition and Change, 293-319. Chicago, Chicago University Press, 1977 .

(1976). "Theory Change as Structure Change: Comments on the Sneed Formalism". Erkenntnis I0: I79-199. Reprinted in Kuhn (2000a): I76-I95.

(1977). The Essential Tension: Selected Studies in Scientific Tradition and Change. Chicago, Chicago University Press.

(I979). "Metaphor in Science". In A. Ortony (ed.), Metaphor and Thought, Cambridge, Cambridge University Press. Reprinted in Kuhn (2000a): 96-207.

(I98I). "What Are Scientific Revolutions?" In L.Krüger et al. (eds.), The Probabilist Revolution, vol. I, Ideas in History, Cambridge, MA, MIT Press, 1987. Reprinted in Kuhn (2000a): 13-32. (I983). "Commensurability, Comparability, Communicability". 
In P.D Asquith and T. Nickles (eds.), PSA I982. Proceedings of the 1982 Biennial Meeting of the Philosophy of Science Association, East Lansing, Philosophy of Science Association. Reprinted in Kuhn (2000a): 3357.

(1989). "Possible Worlds in History of Science". In S. Allén (ed.), Possible Worlds in Humanities, Arts, and Sciences, 9-3I. Berlin, Walter de Gruyter. Reprinted in Kuhn (2000a): 58-89; quoted from the first edition.

(1990). "Dubbing and Redubbing: the Vulnerability of Rigid Designation". In C.W. Savage (ed.), Scientific Theories, 298-3I8. Minnesota, University of Minnesota Press.

(I99I). "The Road since Structure". In A. Fine et al. (eds.), PSA 1990. Proceedings of the 1990 Biennial Meeting of the Philosophy of Science Association, vol. I, East Lansing, Philosophy of Science Association. Reprinted in Kuhn (2000a): 90-IO4

(1993). "Afterwords", in P. Horwich (ed.), World Changes. Thomas Kuhn and the Nature of Science, Cambridge: MIT Press. Reprinted in Kuhn (2000a): 224-252.

(2000a). The Road since Structure, Philosophical Essays 1970-1993, with an Autobiographical Interview. Chicago: Chicago University Press.

(200ob). "A Discussion with Thomas S. Kuhn". In T.S. Kuhn (2000a): 253-323.

Mayoral, J.V. (20I7). Thomas Kuhn. La búsqueda de la estructura. Zaragoza: Universidad de Zaragoza.

Putnam, H. (2015). "Intellectual autobiography of Hilary Putnam”. In R.E. Auxier et al. (eds.), The Philosophy of Hilary Putnam, I-IIo. Chicago, Ill: Open Court. 